University of Nebraska - Lincoln

DigitalCommons@University of Nebraska - Lincoln

\title{
The Influence of Topology on Hydraulic Conductivity in a Sand- and-Gravel Aquifer
}

Roger H. Morin

Denver Federal Center, roger.morin49@gmail.com

Denis R. LeBlanc

U.S. Geological Survey, Northborough

Brent M. Troutman

U.S. Geological Survey, Denver

Follow this and additional works at: https://digitalcommons.unl.edu/usgsstaffpub

Part of the Earth Sciences Commons

Morin, Roger H.; LeBlanc, Denis R.; and Troutman, Brent M., "The Influence of Topology on Hydraulic Conductivity in a Sand-and-Gravel Aquifer" (2010). USGS Staff -- Published Research. 351.

https://digitalcommons.unl.edu/usgsstaffpub/351

This Article is brought to you for free and open access by the US Geological Survey at DigitalCommons@University of Nebraska - Lincoln. It has been accepted for inclusion in USGS Staff -- Published Research by an authorized administrator of DigitalCommons@University of Nebraska - Lincoln. 


\title{
The Influence of Topology on Hydraulic Conductivity in a Sand-and-Gravel Aquifer
}

\author{
by Roger H. Morin ${ }^{1}$, Denis R. LeBlanc ${ }^{2}$, and Brent M. Troutman ${ }^{3}$
}

\begin{abstract}
A field experiment consisting of geophysical logging and tracer testing was conducted in a single well that penetrated a sand-and-gravel aquifer at the U.S. Geological Survey Toxic Substances Hydrology research site on Cape Cod, Massachusetts. Geophysical logs and flowmeter/pumping measurements were obtained to estimate vertical profiles of porosity $\varphi$, hydraulic conductivity $K$, temperature, and bulk electrical conductivity under background, freshwater conditions. Saline-tracer fluid was then injected into the well for $2 \mathrm{~h}$ and its radial migration into the surrounding deposits was monitored by recording an electromagnetic-induction log every $10 \mathrm{~min}$. The field data are analyzed and interpreted primarily through the use of Archie's (1942) law to investigate the role of topological factors such as pore geometry and connectivity, and grain size and packing configuration in regulating fluid flow through these coarse-grained materials. The logs reveal no significant correlation between $K$ and $\varphi$, and imply that groundwater models that link these two properties may not be useful at this site. Rather, it is the distribution and connectivity of the fluid phase as defined by formation factor $F$, cementation index $m$, and tortuosity $\alpha$ that primarily control the hydraulic conductivity. Results show that $F$ correlates well with $K$, thereby indicating that induction logs provide qualitative information on the distribution of hydraulic conductivity. A comparison of $\alpha$, which incorporates porosity data, with $K$ produces only a slightly better correlation and further emphasizes the weak influence of the bulk value of $\varphi$ on $K$.
\end{abstract}

\section{Introduction}

Laboratory studies (e.g., Biella et al. 1983; Huntley 1986) have established well-documented empirical relations for predicting the hydraulic conductivity $K$ of soils and rocks. These typically take the general form:

$$
K=f(R) f(\phi)
$$

and may be defined more specifically as (Nelson 2005):

$$
K=c R^{2} \phi^{b}
$$

${ }^{1}$ Corresponding author: U.S. Geological Survey, Denver, CO 80225; (303) 236-5915; fax: (303) 236-5968; rhmorin@usgs.gov

${ }^{2}$ U.S. Geological Survey, Northborough, MA 01532

${ }^{3}$ U.S. Geological Survey, Denver, CO 80225

Received March 2009, accepted September 2009.

Copyright (c) 2009 The Author(s) are Federal Government Employees

Journal compilation @ 2009 National Ground Water Association. doi: $10.1111 / j .1745-6584.2009 .00646 . x$ where $R$ represents some physical parameter such as porethroat size or hydraulic radius, $\varphi$ is porosity, $b$ is similar to Archie's (1942) cementation exponent, and $c$ is a dimensional term for standardizing variable units. Various interpretations of this relation include versions proposed by Carman (1956) and by Katz and Thompson (1986). The general concept is that the hydraulic conductivity is dependent upon two primary factors: (1) the porosity, and (2) the manner in which porosity is distributed within the porous medium.

To better understand the role of this latter element in controlling $K$, numerous studies have been undertaken to assess the relation between electrical and hydraulic properties of saturated rocks, postulating that particular pathways for the efficient transmission of electric current are analogous to pathways for viscous fluid flow. Empirical relations (e.g., Archie 1942), as well as analytical models (e.g., Hashin and Shtrikman 1962) and pore-geometry simulations (e.g., Herrick and Kennedy 1994; Friedman and Seaton 1998), have been applied to 
predict the electrical conductivity of a two-phase mixture of materials. Guéguen and Palciauskas (1994) provide an informative review of these approaches. Several field investigations (e.g., Heigold et al. 1979; Urish 1981; Purvance and Andricevic 2000) have proposed various correlations between the electrical and the hydraulic conductivities of groundwater systems. Recently, cross-well electrical resistivity tomography has been used to monitor the movement of a saline tracer and estimate its spatial variance (Singha and Gorelick 2005). The general research strategy has been to collect information regarding the pore structure of granular deposits by using electrical measurements and then to apply the results toward understanding the physical mechanisms that control fluid flow.

Building upon this approach, a field experiment was designed and implemented to gain insight into the role of topology, or geometric configuration, on the hydraulic conductivity of a sand-and-gravel aquifer at the U.S. Geological Survey Toxic Substances Hydrology site on Cape Cod, Massachusetts (Figure 1). For more than three decades, this research site has served as a hydrogeological field laboratory for multidisciplinary investigations concerned with the physical, chemical, and microbiological processes that affect groundwater contaminants (LeBlanc 2006; U.S. Geological Survey 2009). The study area is composed of unconsolidated glacial outwashplain sediments deposited during the retreat of Pleistocene ice sheets (Oldale 1981; Uchupi et al. 1996). They consist of stratified, medium-to-coarse surficial sands and some gravels with cross bedding consistent with a braided-stream morphology. These deposits contain less than $1 \%$ silt and clay, and extend to roughly $35 \mathrm{~m}$ depth where they overlie finer, proglacial lake sediments (Masterson et al. 1997).

More than 1000 monitoring wells have been installed in the "gravel pit" study area to accommodate a variety of field experiments and geophysical-logging programs (LeBlanc et al. 1991). Hess et al. (1992) collected and analyzed a comprehensive series of high-resolution flowmeter logs under pumped conditions (Molz et al. 1989) to investigate the spatial variability of hydraulic conductivity $K$, and reported values that ranged over slightly more than one order of magnitude $(0.013$ to $0.37 \mathrm{~cm} / \mathrm{s}$ ). Morin (2006) similarly measured the vertical distribution of hydraulic conductivity and obtained other complementary geophysical logs in an attempt to identify relations among $K$ and other log-derived parameters such as porosity, electrical conductivity, and natural-gamma activity. These data revealed a weak negative to nonexistent correlation between porosity and hydraulic conductivity from which it was inferred that $K$ was influenced more by topological factors intrinsic to the granular mixtures than by the actual volume of the saturating fluid phase, that is, $f(R)$ rather than $f(\varphi)$ in Equation 1.

To further investigate the nature of this phenomenon in coarse-grained materials, a field experiment was designed to exploit the apparent correlation between electrical and hydraulic conductivities. Temperature, neutronporosity, electromagnetic-induction, natural-gamma activity, and flowmeter logs were initially collected in a well

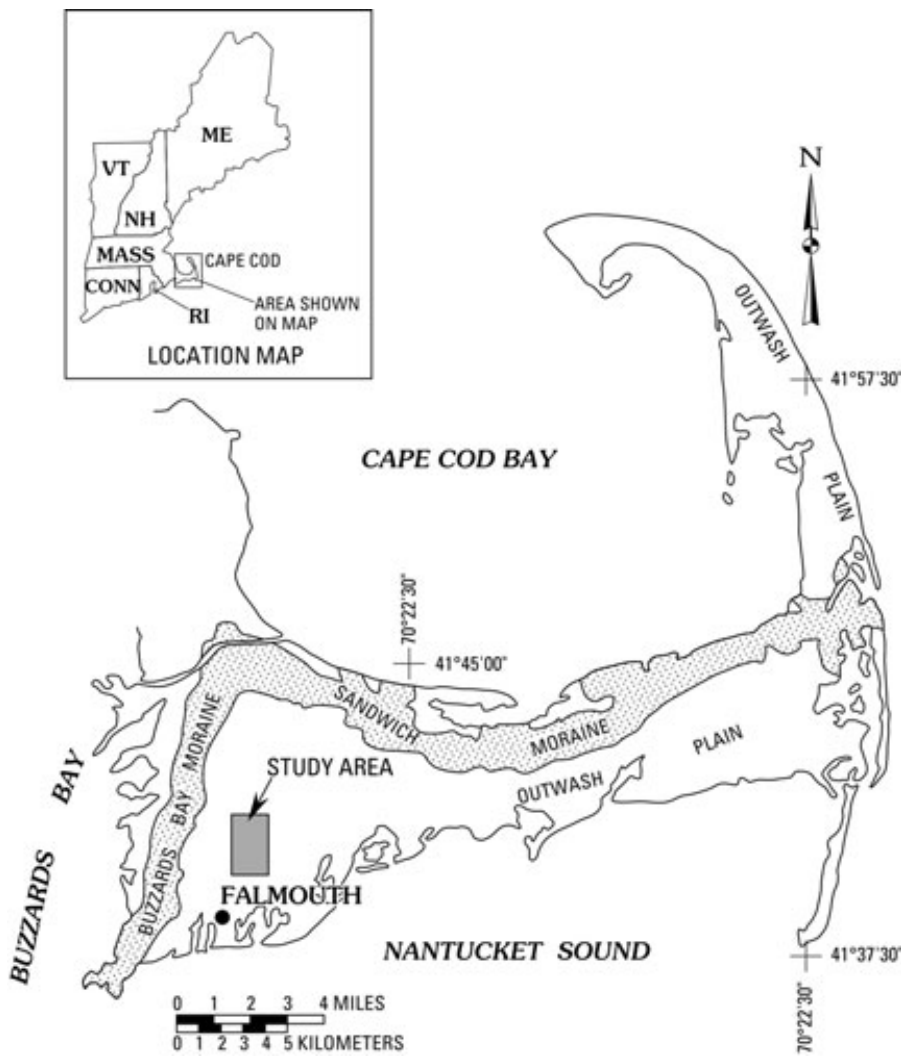

Figure 1. Location of study site. 
(well FSW-416) under ambient, background conditions. Subsequently, the electrical properties of the sediments surrounding this well were substantially elevated by injecting a saline tracer to displace the native groundwater; the movement of this tracer was monitored by recording a sequence of electromagnetic-induction logs in the same well. These electrical-conductivity data combined with the porosity log permit several petrophysical parameters to be computed and interpreted within the context of the $K$ distribution determined from the flowmeter measurements.

\section{Theoretical Formulation}

\section{Electrically Conductive Pore Fluid}

Numerous analytical mixing models have been developed to determine the electrical conductivity of porous media consisting of two or more conducting phases; Glover et al. (2000) summarize several of the more common ones. These models require information regarding the electrical conductivities of the individual conducting phases, their volume fractions, and some measure of their distribution or connectivity. The upper and lower bounds of the bulk effective conductivity, $\sigma_{\text {eff }}$, are constrained by perpendicular and parallel configurations (e.g., Guéguen and Palciauskas 1994), as presented in Equations 3 and 4, respectively:

$$
\begin{gathered}
\frac{1}{\sigma_{\text {eff }}}=\sum_{i=1}^{N} \frac{\lambda_{i}}{\sigma_{i}} \\
\sigma_{\text {eff }}=\sum_{i=1}^{N} \lambda_{i} \sigma_{i}
\end{gathered}
$$

where $\sigma_{i}=$ conductivity of phase $i, \lambda_{i}=$ volume fraction of phase $i$, and $N=$ number of phases. The perpendicular model (Equation 3) defines a harmonic mean and represents a layered structure of materials arranged normal to current flow. The parallel model defines an arithmetic mean, with current flow parallel to the layers. When the porous medium consists of only two components, a fluid phase and a solid phase, Equations 3 and 4 reduce to the following form:

$$
\begin{gathered}
\frac{1}{\sigma_{\text {eff }}}=\frac{\phi}{\sigma_{\mathrm{f}}}+\frac{(1-\phi)}{\sigma_{\mathrm{s}}} \\
\sigma_{\text {eff }}=\phi \sigma_{\mathrm{f}}+(1-\phi) \sigma_{\mathrm{s}}
\end{gathered}
$$

where $\varphi=$ porosity, $\sigma_{\mathrm{f}}=$ conductivity of the fluid phase, and $\sigma_{\mathrm{s}}=$ conductivity of the solid phase.

Archie (1942) derived an empirical expression for the electrical conductivity of saturated rocks based on the ratio of fluid and bulk conductivities, referred to as the formation factor $F$ (Equation 7), and the commonly used Archie's law (Equation 8) was originally developed from measurements on clean sandstones saturated with highly conductive saline solutions:

$$
F=\frac{\sigma_{\mathrm{f}}}{\sigma_{\text {eff }}}
$$

$$
F=a \phi^{-m}
$$

where the constant $a$ is related to rock type and is often determined through regression methods. This relation assumes conduction through the fluid phase only; the electrical conductivity of the solids, $\sigma_{\mathrm{s}}$, is considered to be negligible. It also assumes that the effective porosity is the total porosity; that is, there are no isolated pores. The exponent $m$ was originally termed the cementation index because it was found to increase with the degree of cementation. Consequently, large values of $m(>2)$ occur where connectivity of the fluid phase is poor and small values $(<2)$ are apparent where connectivity is high (Glover et al. 2000).

The formation factor is an intrinsic property that remains constant with varying fluid conductivity when values of $\sigma_{\mathrm{f}}$ are large, and it is considered to be an indication of the geometrical configuration of the porous material. An increase in the magnitude of $F$ represents an increase in the tortuosity, $\alpha$, of the current path as defined by Carman (1937):

$$
\alpha=\left(\frac{L_{\mathrm{e}}}{L}\right)^{2} \geq 1
$$

where $L_{\mathrm{e}}$ is the effective flow length through the pore pathways and $L$ is the straight-path length. $F$ and $\alpha$ are related by the following expression (e.g., Nelson 1994; Lesmes and Friedman 2006):

$$
\alpha=F \phi
$$

The tortuosity index provides a measure of the effects of pore constrictions and shapes, and the sinuous pathways interrupted by grains. Guéguen and Palciauskas (1994) present the analogous fluid-flow case for capillary tubes having uniform cross sections and oriented parallel to the hydraulic gradient. In this ideal case, $\alpha=1$ because $L_{\mathrm{e}}$ equals $L$ (no tortuosity). The magnitude of $\alpha$ becomes greater than 1 as the variability of the tube diameters increases.

\section{Electrically Resistive Pore Fluid}

In most aquifers used for water supply, the saturating pore fluid is fairly fresh (resistive) and its electrical conductivity is not so high as to completely dominate current flow (e.g., Kosinski and Kelly 1981; Urish 1981). In this case, Archie's law breaks down (Hearst et al. 2000 ) because surface conductivity along grain boundaries becomes a significant component of the bulk effective conductivity. Laboratory tests performed by Biella et al. (1983) under controlled conditions showed that this transformation began to occur when fluid conductivity dropped below roughly $800 \mu \mathrm{S} / \mathrm{cm}$. As such, the measured value of the formation factor decreases in freshwater environments and Archie's law consistently underpredicts the magnitude of the bulk electrical conductivity.

This effect was recognized in laboratory experiments (e.g., Waxman and Smits 1968; Huntley 1986) and an additional term was added to the conventional Archie's 
law by assuming that surface conductivity, $\sigma_{\text {surface }}$, is composed of parallel and statistically similar conductive pathways through the interconnected pore fluid and along the grain boundaries when $\sigma_{\mathrm{f}}$ is low. Consequently, a second component is added to the parallel conductivity model of Equation 6 and the relation becomes as follows:

$$
\sigma_{\text {eff }}=\frac{\sigma_{\mathrm{f}}}{F}+\sigma_{\text {surface }}
$$

Numerous theoretical and experimental studies have examined the nature of the surface conductivity in porous rocks. Surface conductivity may be dependent upon clay content, specific surface area, and surface chemical properties at the solid-liquid interface. Waxman and Smits (1968) defined it principally in terms of clay content and the cation exchange capacity per unit pore volume. Other investigators have defined the surface conductivity in terms of the electrical double layer, solution $\mathrm{pH}$, and surface chemical reactions (e.g., Pride 1994; Revil and Glover 1998). It can be presented in the general form:

$$
\sigma_{\text {surface }}=\frac{\psi}{F}
$$

and, substituting into Equation 11, takes the following form:

$$
\sigma_{\text {eff }}=\frac{1}{F^{*}}\left(\sigma_{\mathrm{f}}+\psi\right)
$$

Because the conventional formation factor $F$ is only applicable when surface conductivity is negligible (conductive pore fluid), its use in the aforementioned equation is not strictly valid when $\sigma_{\mathrm{f}}$ is low (freshwater) and $\psi$ becomes more dominant. It is therefore replaced by a modified version $F^{*}$ that may be determined experimentally (Guéguen and Palciauskas 1994). Typically, the surface conductivity increases with increasing specific surface area; consequently, $\psi$ increases with decreasing grain size and becomes more prominent in fine-grained materials.

Thus, the relation between electrical and hydraulic properties $\left(\sigma_{\text {eff }}\right.$ and $\left.K\right)$ can be separated into two general categories based upon the electrical conductivity of the saturating fluid: (1) $\sigma_{\mathrm{f}}$ is high such that the bulk electrical conductivity of the saturated medium is captured by the fluid phase. If $F$ is a function of porosity (Equation 8) and if $K$ is also assumed to be a function of porosity (Equations 1 and 2), then $K$ and $\sigma_{\text {eff }}$ may be positively correlated. (2) $\sigma_{\mathrm{f}}$ is low such that surface conductivity along grain boundaries emerges as an important pathway for current flow. If the bulk electrical conductivity increases with decreasing grain size (e.g., Wildenschild et al. 2000) and if $K$ decreases with decreasing grain size (e.g., Shepherd 1989; Chapuis 2004), then $K$ and $\sigma_{\text {eff }}$ may be negatively correlated. Purvance and Andricevic (2000) present examples where both types of conditions have been reported in aquifer studies.

\section{Field Methods}

A saline-tracer injection experiment was performed in a well (well FSW-416) constructed of slotted 5.1-cm

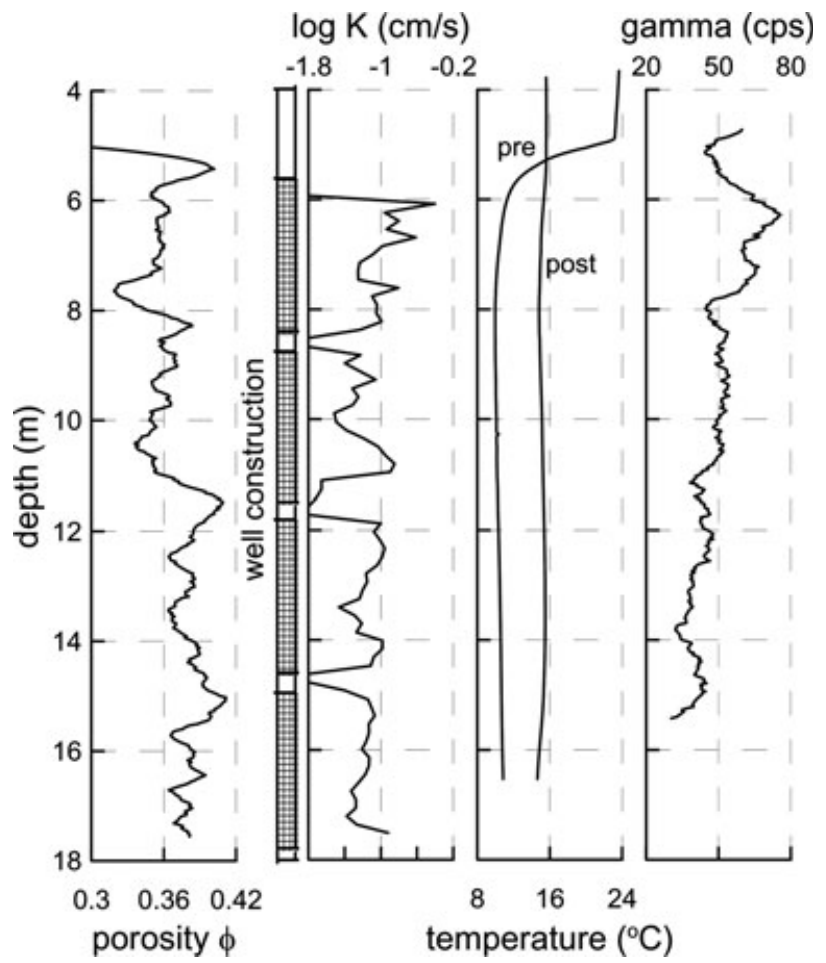

Figure 2. Neutron-porosity, hydraulic conductivity, temperature, and natural-gamma (counts per second) logs, with diagram of well construction. Note that sharp decreases in $K$ coincide with sections of blank casing.

(2-inch) PVC casing to a total depth of $17.5 \mathrm{~m}$ (all depths reported in meters below land surface). The slotted PVC casing was constructed in 3-m (10-foot) lengths, with 0.15-m-long (6-inch) blank sections at each end. A wellconstruction diagram is included in Figure 2 alongside the geophysical $\operatorname{logs}$ and is also repeated in several other figures for reference. The well was installed by means of a hammer-driving technique to minimize disturbance to the surrounding aquifer fabric (Morin et al. 1988) and optimize the accuracy of the geophysical-log responses. Consequently, no core samples were taken in this well to determine grain-size distributions. However, previous measurements on samples collected near this well by Wolf et al. (1991) show mean values of $d_{10}$ and $d_{50}$ (grain diameters at which $10 \%$ and $50 \%$ by weight are of smaller size) to be about 0.2 and $0.5 \mathrm{~mm}$, respectively.

Pre-injection logging operations consisted of obtaining temperature, natural-gamma, and neutron-porosity logs (Hearst et al. 2000) as well as a hydraulic-conductivity profile estimated from a flowmeter log recorded under pumped conditions (Molz et al. 1989); no ambient flow was detected in this well. The single detector in the neutron-porosity tool responds in an inverse logarithmic manner to water content and was calibrated over a wide range of porosities in specially designed pits. A post-injection temperature log was also obtained to reference fluid-conductivity measurements to a common in situ temperature. These data are displayed in Figure 2, where sharp reductions in values of $K$ coincide with the sections of blank casing; the porosity, natural-gamma, and 
temperature logs are not affected by these blank intervals. The water level was $4.9 \mathrm{~m}$ below land surface and its location is delineated by the marked shifts in the porosity and pre-injection temperature profiles. The electrical conductivity of the ambient, native groundwater was about 80 $\mu \mathrm{S} / \mathrm{cm}$ at in situ temperature and found to be relatively uniform with depth.

An electromagnetic-induction tool was used to measure the bulk electrical conductivity of the saturated deposits surrounding the well. This instrument operates at a frequency of $40 \mathrm{kHz}$ and yields a measure of apparent electrical conductivity based upon primary and quadrature secondary receiver voltages. About half of the tool's sampling volume originates within $45 \mathrm{~cm}$ radially of the well, and its theory and principle of operation are presented by Hearst et al. (2000). After obtaining an initial conductivity log to record background conditions, a saline-tracer fluid having a conductivity of $6200 \mu \mathrm{S} / \mathrm{cm}$ (corrected to in situ, post-injection temperature in the well; see Figure 2) was injected at a rate of $28 \mathrm{~L} / \mathrm{min}$ with the logging tool remaining in the well. The tracer fluid was fed through a hose that initially extended to the bottom of the well and then was slowly raised so that the saline fluid gradually filled the entire well from the bottom to the top after a few minutes. Injection continued at this rate for $2 \mathrm{~h}$ and induction $\operatorname{logs}$ were recorded every $10 \mathrm{~min}$. The resulting time series of induction logs is presented in Figure 3, with the composite following the gradual migration of the

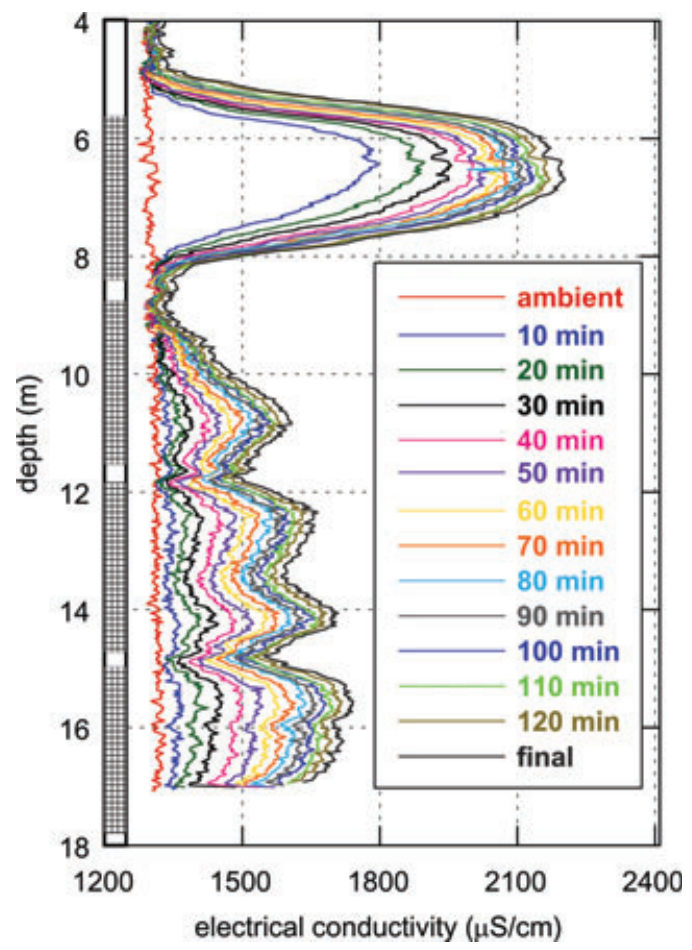

Figure 3. Time series showing induction logs collected every $10 \mathrm{~min}$ for $\mathbf{2} \mathrm{h}$. Also included are the initial conductivity profile recorded before the start of injection and the final log representing steady-state conditions once the saline tracer has displaced native groundwater in sampling volume. saline fluid radially from the well as it displaces the native groundwater.

A comparison of induction $\log$ s recorded at 110 and $120 \mathrm{~min}$ shows that steady-state conditions (total saturation of the sample volume) were not fully reached after $2 \mathrm{~h}$ of injection. However, an exponential increase in time-series conductivities monitored at individual depths indicates that the last recorded log (120 min) approached $95 \%$ of the steady-state value, and a similar but longerterm injection test conducted at a nearby well confirmed this approximation. Thus, the log labeled as "final" in Figure 3 has been adjusted based upon this response to represent steady-state conditions. Again, sections of blank casing impair the tracer movement and cause conductivity profiles to pinch in at depths coincident with these intervals.

The tracer was produced by mixing enough $\mathrm{NaCl}$ in tanks filled with freshwater to yield a substantial contrast in electrical conductivity that spanned almost two orders of magnitude. In this paper, we consider only the preand post-injection conductivity logs that represent endmember electrical conditions; the time-series data will be analyzed as part of a future study.

\section{Log Analysis and Results}

The natural-gamma log displayed in Figure 2 depicts relatively low activity for most of the well $(\leq 55$ counts per second), but with an interval of slightly higher activity across the interval from 6.0 to $7.5 \mathrm{~m}$. Because of the lack of clays at this site, Morin (2006) postulated that this elevated gamma signal may indicate the presence of coarse, immature glauconitic sands. This zone also corresponds to higher values of hydraulic conductivity and the coincident responses may be related to grain size. A comparison of the hydraulic-conductivity profile derived from the flowmeter logs with the porosity log recorded in this well (Figure 2) illustrates that there are narrow intervals where $K$ and $\varphi$ are seen to be either positively or negatively correlated (Figure 4). However, a cross plot of these data encompassing the entire well shows no significant correlation between these two physical properties ( $R=0.190$; Figure 5$)$. From this lack of interdependence, Morin (2006) inferred that the hydraulic conductivity of these unconsolidated materials is related more to the packing arrangement and connectivity of the pores than to the bulk volume fraction of the fluid phase; that is, $f(R)$ overrides $f(\varphi)$ in Equation 1 .

To better understand the nature of this phenomenon, several of the predominant petrophysical or topological characteristics of these granular deposits are examined. These are determined primarily from the final electricalconductivity profile because this log represents the experimental state when most of the sediments were saturated with the saline tracer; that is, all electrical current is being transmitted through the fluid phase and Archie's law (Equations 7 and 8) is valid.

Before values for these parameters can be computed, however, the particular measurement specifications of the 


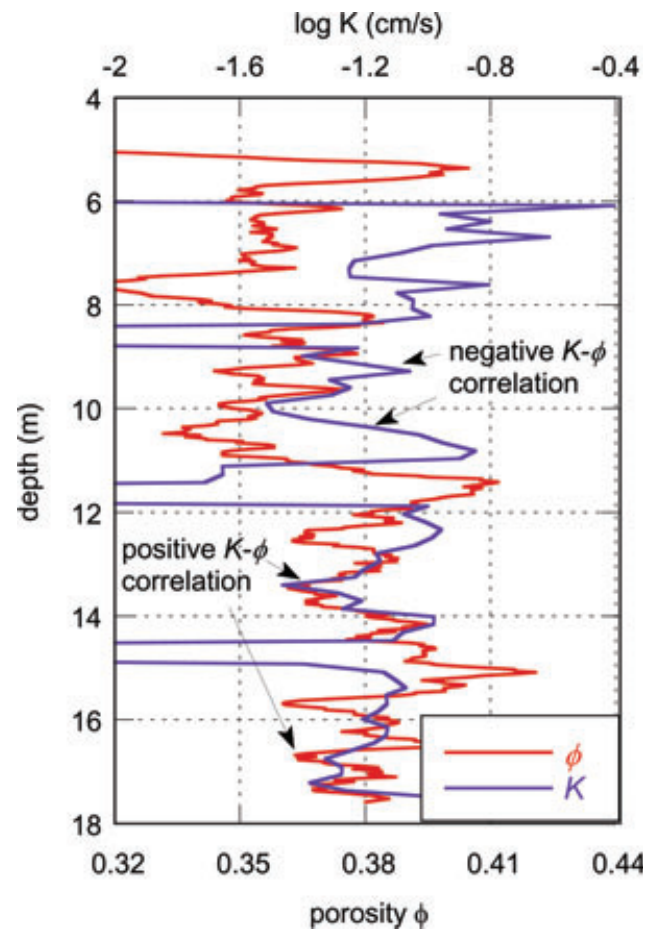

Figure 4. Superposed profiles of hydraulic conductivity $K$ and porosity $\varphi$ from Figure 2. Hydraulic conductivity scale ranges from 0.01 to $0.40 \mathrm{~cm} / \mathrm{s}$.

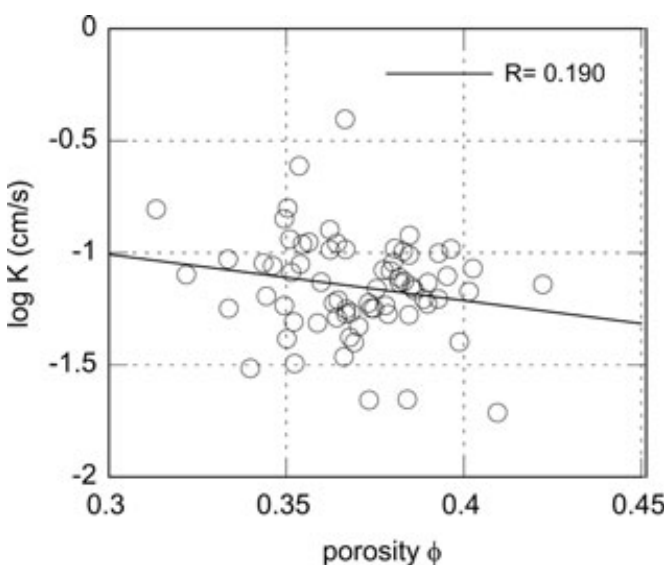

Figure 5. Cross plot of hydraulic conductivity and porosity data across entire well showing no strong interdependence $(R=0.190)$, although some narrow intervals do exhibit negative or positive correlations (see Figure 4).

induction tool must be considered. The vertical bed resolution for this instrument is presented in Figure 6 and illustrates that a conductive layer is recognized by the tool as an asymmetrical bell-shaped curve that extends across about $3 \mathrm{~m}$ vertically. This laboratory calibration response has been provided by the tool manufacturer and is determined specifically for a 50 -cm-thick bed. Consequently, it is this thickness that constrains the vertical resolution of our data inversion scheme. Using a convolution algorithm that incorporates an asymmetrically weighted function

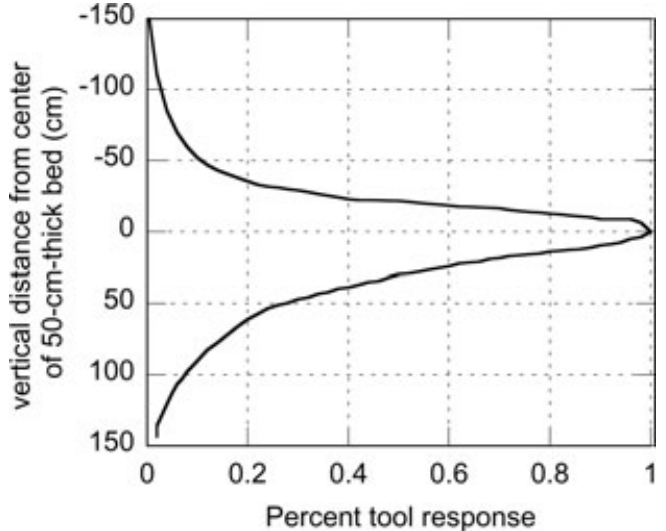

Figure 6. Vertical bed response of induction tool to a 50cm-thick conductive layer.

and applies it against the final induction log, a leastsquares analysis is used to generate a series of layers, each assigned with a particular value of electrical conductivity.

To accomplish this data inversion, we first define the following variables: $y_{i}=$ depth of $i$ th well-log measurement $(\mathrm{cm}) ; s_{i}=i$ th induction-log measurement $(\mu \mathrm{S} / \mathrm{cm})$; $\hat{y}_{j}=$ depth of midpoint of $j$ th layer for which electrical conductivity is to be estimated (cm); $\sigma_{j}=$ electrical conductivity for $j$ th layer $(\mu \mathrm{S} / \mathrm{cm}) ; \hat{\sigma}_{j}=$ final electrical conductivity for $j$ th layer determined by least-squares analysis $(\mu \mathrm{S} / \mathrm{cm})$; and $h(d)=$ tool response at vertical distance $d(\mathrm{~cm})$.

$$
w_{i j}=\frac{h\left(y_{i}-\hat{y}_{j}\right)}{\sum_{j} h\left(y_{i}-\hat{y}_{j}\right)}
$$

Here, the variable $w_{i j}$ is a weight that represents the magnitude of the effect of the $j$ th layer on the $i$ th observed well-log measurement; this effect is proportional to the tool response function evaluated at the difference between depths $y_{i}$ and $\hat{y}_{j}$. Note that division by the summation function normalizes the weights $w_{i j}$ for each $i$, so that $\sum_{j} w_{i j}=1$.

For any combination of electrical conductivities $\sigma_{j}$, the estimated conductivity corresponding to the $i$ th well$\log$ measurement is $\sum_{j} w_{i j} \sigma_{j}$. The final values of $\hat{\sigma}_{j}$ are then those values of $\sigma_{j}$ that minimize the sum-of-squares objective function $S$ :

$$
S=\sum_{i}\left(s_{i}-\sum_{j} w_{i j} \sigma_{j}\right)^{2}
$$

The plot in Figure 7 shows these values of $\hat{\sigma}_{j}$ for each $50-\mathrm{cm}$ layer superposed upon the original induction log. This stack represents and reproduces the field profile once the vertical tool response has been taken into account. Suppressed values of $\hat{\sigma}_{j}$ are aligned with sections of blank casing where tracer injection was blocked.

The conductivity of the tracer $\left(\sigma_{\mathrm{f}}=6200 \mu \mathrm{S} / \mathrm{cm}\right)$ is divided by these inversion-derived conductivity values to 


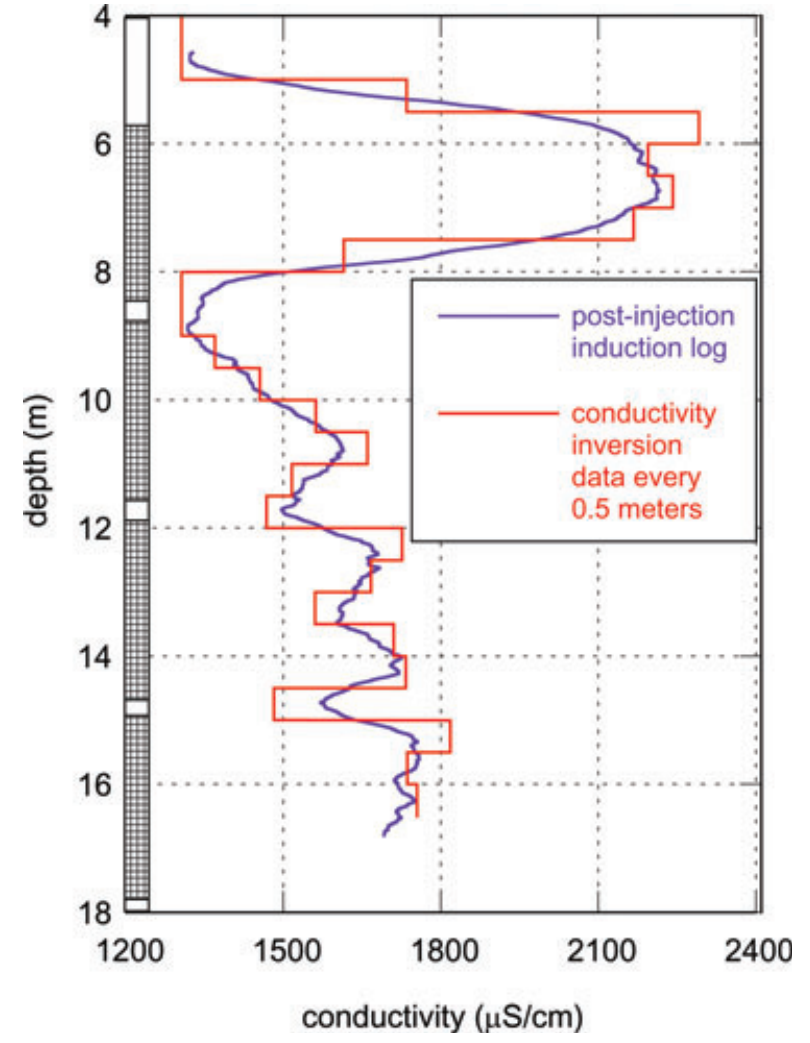

Figure 7. Results of inversion of post-injection induction log (Figure 3, final profile) based on vertical tool calibration (Figure 6) and sum-of-squares function. A stack of $50-\mathrm{cm}$ thick layers is shown superposed on induction log.

produce a profile of formation factor $F$ at $50-\mathrm{cm}$ depth intervals (Equation 7; Figure 8a). With the value of the constant $a$ (Equation 8) set to unity, these data are subsequently combined with the porosity log averaged across $50-\mathrm{cm}$ sections to generate profiles of the cementation factor $m$ (Equation 8; Figure 8b) and the tortuosity $\alpha$ (Equation 10; Figure 8c). Because of the paucity of clays at this site (e.g., Wolf et al. 1991; Garabedian et al. 1991) and little associated bound water and ionic double layers, values of porosity determined with the neutron-porosity tool are assumed to record total interconnected porosity with no isolated pores. Again, the sections of blank casing in this well impeded the tracer from flowing radially into the surrounding sediments, and the values of $F, m$, and $\alpha$ coincident with these intervals are not representative of the aquifer properties; they are artifacts of the well construction.

For most of the well (below a depth of $8 \mathrm{~m}$ ), the magnitude of $F$ ranges between approximately 3.5 and 4.8. These values are typical for unconsolidated deposits where the packing arrangement is loose and electrical resistance is small (Jackson et al. 1978); values of formation factor for consolidated, low-permeability rocks can reach 100 (Hearst et al. 2000). Across this same lower section, values of $m$ range from about 1.2 to 1.6 and are also typical of granular mixtures (e.g., Kwader 1985). The profile of $\alpha$ reflects the presence of unconsolidated

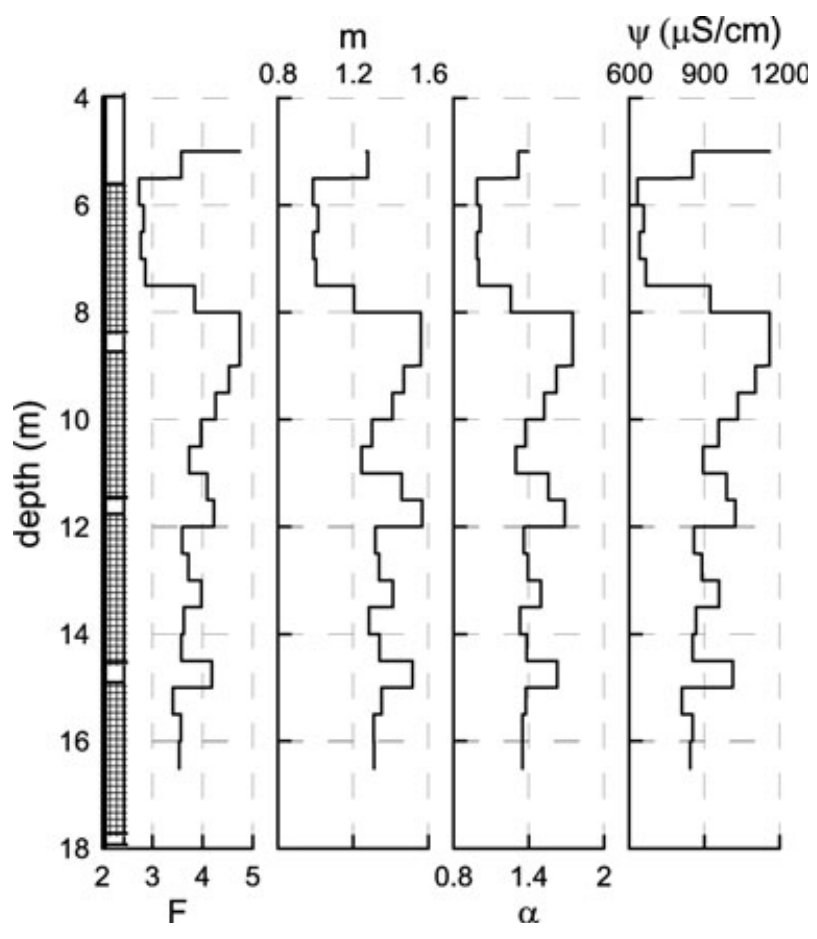

Figure 8. Vertical profiles of (a) formation factor $F$, (b) cementation factor $m$, (c) tortuosity $\alpha$, and (d) surface conductivity $\psi(\mu \mathrm{S} / \mathrm{cm})$.

sediments, with larger values corresponding to finergrained deposits and elongated pathways.

Data originating from the upper few meters of the well describe a markedly different granular mixture. Values of $F$ are lower than typical $(<3.0)$, indicating minimal resistance to current flow; correspondingly, values of $m$ across this section decrease to about 1.0 and the empirically derived Archie's law (Equation 8) reduces to the parallel conduction model (Equation 6). Under these conditions, the tortuosity is also equal to unity (Equation 10). A value of 1 for $\alpha$ describes a hydraulic case that is conceptually equivalent to flow through capillary tubes of uniform diameter (Guéguen and Palciauskas 1994) because the effective flow length around grains is equal to the straight line path length (Equation 9). Consequently, the hydraulic conductivity is expected to be substantially higher across this upper zone.

Additional topological information can be gleaned by evaluating the surface conductivity along grain boundaries from the induction log recorded in the freshwater aquifer prior to injection of the saline tracer (Figure 3, ambient profile). Although there are few clays observed in these sand-and-gravel deposits to enhance conduction pathways, laboratory and field studies have shown that lead, nickel, and zinc are strongly attenuated and retarded in groundwater at Cape Cod owing to their propensity to adsorb on grain surfaces (Coston et al. 1995; Davis et al. 1998). Adsorption of these metal ions on sediments varies with $\mathrm{pH}$, and a set of models that describes quantitatively the extent of this adsorption over a range of $\mathrm{pH}$ values has 
been presented by Kent et al. (2007). These chemical processes likely account for most of the surface conductivity detected in sediments at this site.

Referring to Equation 13, the surface conductivity component of $\sigma_{\text {eff }}$, as represented by the variable $\psi$, is not known for these sediments a priori. However, $F^{*}$ is always recognized to be smaller than $F$ (Hearst et al. 2000) and has been determined from laboratory experiments on a variety of rock samples saturated with fluids of variable conductivity. Evers and Iyer (1975) presented values for $F / F^{*}$ ranging from about 4 to 6 for clean sandstones for the case where $\sigma_{\mathrm{f}}$ equals about 80 $\mu \mathrm{S} / \mathrm{cm}$, the conductivity of the native groundwater at our study site. Similarly, Keller (1987) reported reductions in formation factor of about $80 \%$ for rocks having few clays and saturated with fluid having this same $80 \mu \mathrm{S} / \mathrm{cm}$ conductivity. Based upon these results, we assume for our purposes that $F / F^{*}=5$ and compute the vertical distribution of $\psi$ by using values of $F$ derived from tracer-saturated conditions (Figure 8a). The magnitude of this surface conductivity term is related to the specific surface area of the granular mixture and represents, in a qualitative sense, a measure of the grain-size distribution. A profile of $\psi$ is presented in Figure 8d that mimics the general pattern with respect to depth exhibited by the other petrophysical parameters. This plot illustrates that the deposits generally become finer upward, but that this trend reverses in the upper few meters whereupon the sediments are particularly coarse.

All four topological variables obtained from the analysis of neutron-porosity and induction $\operatorname{logs}(F, m, \alpha$, and $\psi$ ) display similar trends with depth and provide information related in some manner to pore geometry and connectivity, grain-size distribution, and packing arrangement (Figure 8). In turn, these physical characteristics affect viscous fluid flow and should, therefore, be related to hydraulic conductivity, that is, the relative influence of $f(R)$ in Equation 1. In the upper part of the well (above $8 \mathrm{~m}$ ), the physical mechanism by which values of $m$ and $\alpha$ can approach unity also defines an analogous model for efficient and unobstructed fluid flow through tubes of uniform diameter. This interpretation is supported by the independently acquired profile of $K$ that displays a fourfold increase in hydraulic conductivity near the surface (Figure 2). At depths below $8 \mathrm{~m}$, values of $F, m, \alpha$, and $\psi$ are consistently larger than in the upper part of the well. These larger values are indicative of more constrictions in pore geometry, finer grains, and more sinuous pathways; consequently, values of $K$ are lower.

This apparent correlation between topological parameters and hydraulic conductivities can be investigated further by comparing the vertical distribution of $K$ in this well with any of the profiles displayed in Figure 8. We begin by examining the formation factor and evaluating the effectiveness of the induction log alone in predicting hydraulic conductivity. Values of hydraulic conductivity were averaged across $50-\mathrm{cm}$ depth intervals in order to match the vertical resolution of the formation-factor data,

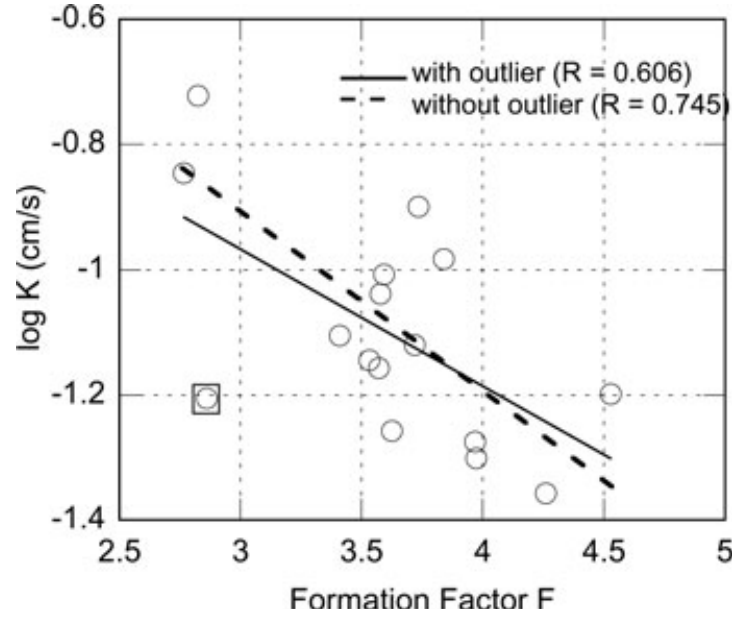

Figure 9. Cross plots of $K$ versus $F(R=0.606)$ with outlier identified in square (corresponding to 7.0 to $7.5 \mathrm{~m}$ interval in well) and without outlier $(R=0.745)$.

and the resulting cross plot (Figure 9) depicts a negative relation between $K$ and $F(R=0.606)$.

One conspicuous outlier point in Figure 9 (shown enclosed within a square) corresponds to a depth interval $(7.0$ to $7.5 \mathrm{~m})$ where a small value of formation factor is uncharacteristically associated with a low value of hydraulic conductivity. We postulate that this anomalous condition may be due to transverse dispersion caused by a slow fluid-velocity zone bounded above and below by fast fluid velocities produced during injection. Because hydrodynamic dispersion is directly dependent upon fluid velocity (e.g., Bijeljic and Blunt 2007; Maier et al. 2008), the tracer may propagate into adjacent zones and cause an increase in bulk electrical conductivity as measured by the induction tool. The manifestation of this dispersion effect may also be seen in the induction profiles at depths aligned with the sections of blank casing. As illustrated in Figure 3, although no tracer was directly injected across these intervals, the electrical conductivities of the saturated deposits did not remain at background levels $(\approx 1300 \mu \mathrm{S} / \mathrm{cm})$ at depths coincident with the two lower blank sections. If the outlier point is eliminated from the cross plot in Figure 9, the resulting correlation coefficient between $K$ and $F$ improves significantly $(R=0.745)$.

The formation factor is computed directly from the induction log (Equation 7) without requiring any estimate of porosity. To insert porosity into this analysis and investigate its influence on hydraulic conductivity, we now compare the profiles of hydraulic conductivity and tortuosity because the computation of $\alpha$ includes $\varphi$ data (Equation 10). The correlations with $(R=0.638)$ and without the outlier point $(R=0.817)$ are only slightly better than those determined between $K$ and $F$ (Figure 9), and support the hypothesis that porosity is of secondary importance in controlling the hydraulic conductivity of sediments at this site. 


\section{Conclusions}

An injection experiment was designed and attempted based on applying principles established under controlled laboratory conditions to field situations. This test demonstrates how a select set of geophysical well logs can be analyzed to yield information regarding the topological properties of a sand-and-gravel aquifer provided that the saturating fluid is electrically conductive. In freshwater environments, this is typically not the case and the assumption that all electric current is being transmitted through the fluid phase is not valid. However, injection of a saline tracer having an elevated electrical conductivity can provide the proper conditions for electromagnetic-induction logging and the application of Archie's (1942) law. Complementary logs that measure porosity and hydraulic conductivity are critical to expanding the general interpretation of the induction logs and investigating the link between flow and topology, for example, coarser or finer grains, capillary flow structure or sinuous flow paths, loose grains or cemented contacts.

The hydraulic-electric transport analog provides insight into how topological properties affect fluid flow through unconsolidated deposits. These factors are manifested as resistance to the transmission of electric current, or as electrical efficiency. One measure of this efficiency is the formation factor and results show that $F$ correlates well with $K$, thereby indicating that induction logs alone provide qualitative information on the distribution of hydraulic conductivity. Tortuosity is another measure; it incorporates porosity information and relates the equivalent flow path around a mixture of grains to the straightpath length. A comparison between $\alpha$ and $K$ produces only a slightly better correlation than that derived from the $F$ and $K$ data, and indicates that $\varphi$ does not have a predominant influence on the hydraulic conductivity.

Results generated from this field method demonstrate its utility in providing information regarding the nature of fluid flow through granular mixtures. However, dispersion effects associated with the forced injection of a tracer may be problematic across intervals exhibiting large contrasts in fluid velocities, either caused naturally by hydrostratigraphic zonation or artificially by sections of blank casing. Numerous tracer tests have been conducted at this site (e.g., Garabedian et al. 1991; Smith et al. 2004) for a variety of investigations, and the presence of distinct, segregated facies may enhance dispersion locally and, consequently, influence these log interpretations. Furthermore, the well-installation method used for this study precluded the collection of core samples and limited our ability to examine grain-size distributions directly.

The initial, pre-injection well $\operatorname{logs}$ show $K$ and $\varphi$ to be poorly correlated, thereby implying that groundwater models that rely to some degree on a particular relation between these two properties may not be useful at this site. Bulk porosity alone does not exert primary control on groundwater movement. Rather, the distribution and connectivity of the porosity as manifested by topological parameters provide a physical basis for understanding the nature of fluid flow through these unconsolidated deposits.

\section{Acknowledgments}

This research was supported by the USGS National Research Program and the Toxic Substances Hydrology Program. The authors are grateful to Philip Nelson, John Williams, David Hart, and an anonymous reviewer for their thorough and thoughtful reviews that improved this manuscript considerably, and also to K.M. Hess for access to field data from this site. Field assistance was provided by B. Corland, G. Fairchild, and J. Gerber of the USGS. The loan of a truck-mounted tracer tank from the Massachusetts Division of Fisheries and Wildlife is also gratefully acknowledged.

\section{References}

Archie, G.E. 1942. The electrical resistivity log as an aid in determining some reservoir characteristics. Transactions, American Institute of Mining, Metallurgy and Petroleum Engineering 146, 54-62.

Biella, G., A. Lozej, and I. Tabacco. 1983. Experimental study of some hydrogeophysical properties of unconsolidated porous media. Ground Water 21, no. 6: 741-751.

Bijeljic, B., and M.J. Blunt. 2007. Pore-scale modeling of transverse dispersion in porous media. Water Resources Research 43, no. W12S11: 8, doi10.1029/2006WR 005700.

Carman, P.C. 1956. Flow of Gases through Porous Media, 182. New York: Academic Press.

Carman, P.C. 1937. Fluid flow through granular beds. Transactions, Institute of Chemical Engineering 15, 150.

Chapuis, R.P. 2004. Predicting the saturated hydraulic conductivity of sand and gravel using effective diameter and void ratio. Canadian Geotechnical Journal 41, 787-795.

Coston, J.A., C.C. Fuller, and J.A. Davis. 1995. $\mathrm{Pb}^{2+}$ and $\mathrm{Zn}^{2+}$ adsorption by a natural aluminum- and iron-bearing surface coating on an aquifer sand. Geochemica et Cosmochemica Acta 59, no. 17: 3535-3547.

Davis, J.A., J.A. Coston, D.B. Kent, and C.C. Fuller. 1998. Application of the surface complexation concept to complex mineral assemblages. Environmental Science and Technology 32, no. 19: 2820-2828.

Evers, J.F., and B.G. Iyer. 1975. Quantification of surface conductivity in clean sandstones. Society of Professional Well Log Analysts 16th Annual Logging Symposium, paper L: $11 \mathrm{pp}$.

Friedman, S.P., and N.A. Seaton. 1998. Critical path analysis of the relationship between permeability and electrical conductivity of three-dimensional pore networks. Water Resources Research 34, no. 7: 1703-1710.

Garabedian, S.P., D.R. LeBlanc, L.W. Gelhar, and M.A. Celia. 1991. Large-scale natural-gradient tracer test in sand and gravel, Cape Cod, Massachusetts: 2. Analysis of spatial moments for a nonreactive tracer. Water Resources Research 27, no. 5: 911-924.

Glover, P.W.J., M.J. Hole, and J. Pous. 2000. A modified Archie's law for two conducting phases. Earth and Planetary Science Letters 180, 369-383.

Guéguen, Y., and V. Palciauskas. 1994. Introduction to the Physics of Rocks, 294. Princeton, New Jersey: Princeton University Press.

Hashin, Z., and S. Shtrikman. 1962. A variational approach to the theory of effective magnetic permeability of multiphase materials. Journal of Applied Physics 33, 3125-3131. 
Hearst, J.R., P.H. Nelson, and F.L. Paillet. 2000. Well Logging for Physical Properties, 483. New York: John Wiley and Sons.

Heigold, P.C., R.H. Gilkeson, K. Cartwright, and P.C. Reed. 1979. Aquifer transmissivity from surficial electrical methods. Ground Water 17, no. 4: 338-345.

Herrick, D.C., and W.D. Kennedy. 1994. Electrical efficiency-a pore geometric theory for interpreting the electrical properties of reservoir rocks. Geophysics 59, no. 6: 918-927.

Hess, K.M., S.H. Wolf, and M.A. Celia. 1992. Large-scale natural gradient tracer test in sand and gravel, Cape Cod, Massachusetts: 3. Hydraulic-conductivity variability and calculated macrodispersivities. Water Resources Research 28, no. 8: 2011-2027.

Huntley, D. 1986. Relations between permeability and electrical resistivity in granular aquifers. Ground Water 24, no. 4: 466-474.

Jackson, P.D., D. Taylor Smith, and P.N. Stanford. 1978. Resistivity-porosity-particle shape relationships for marine sands. Geophysics 43, no. 6: 1250-1268.

Katz, A.J., and A.H. Thompson. 1986. Quantitative prediction of permeability in porous rock. Physical Review B 34, no. 11: 8179-8181.

Keller, G.V. 1987. Rock and mineral properties. In Electromagnetic Methods in Applied Geophysics, vol. 1 of Investigations in Geophysics Series, ed. M.N. Nabighian. Tulsa, Oklahoma: Society of Exploration Geophysicists.

Kent, D.B., J.A. Wilkie, and J.A. Davis. 2007. Modeling the movement of a $\mathrm{pH}$ perturbation and its impact on adsorbed zinc and phosphate in a wastewater-contaminated aquifer. Water Resources Research 43, no. W07440m: 17, doi10.1029/2005WR004841.

Kosinski, W.K., and W.E. Kelly. 1981. Geoelectric soundings for predicting aquifer properties. Ground Water 19, no. 2: 163-171.

Kwader, T. 1985. Estimating aquifer permeability from formation resistivity factors. Ground Water 23, no. 6: 762-766.

LeBlanc, D.R. 2006. Cape Cod Toxic Substances Hydrology Research Site: Physical, chemical, and biological processes that control the fate of contaminants in ground water. USGS Fact Sheet 2006-3096.

LeBlanc, D.R., S.P. Garabedian, K.M. Hess, L.W. Gelhar, R.D. Quadri, K.G. Stollenwerk, and W.W. Wood. 1991. Largescale natural-gradient tracer test in sand and gravel, Cape Cod, Massachusetts: 1. Experimental design and observed tracer movement. Water Resources Research 27, no. 5: 895-910.

Lesmes, D.P., and S.P. Friedman. 2006. Relationships between the electrical and hydrogeological properties of rocks and soils. In Hydrogeophysics, eds. Y. Rubin and S.S. Hubbard, 87-128. The Netherlands: Springer.

Maier, R.S., M.R. Schure, J.P. Gage, and J.D. Seymour. 2008. Sensitivity of pore-scale dispersion to the construction of random bead packs. Water Resources Research 44, no. W06S03: 12, doi10.1029/2006WR005577.

Masterson, J.P., B.D. Stone, D.A. Walter, and J. Savoie. 1997. Hydrogeologic framework of western Cape Cod, Massachusetts. USGS Hydrologic-Investigations Atlas HA 741, 1 plate.

Molz, F.J., R.H. Morin, A.E. Hess, J.G. Melville, and O. Güven. 1989. The impeller meter for measuring aquifer permeabil- ity variations: Evaluation and comparison with other tests. Water Resources Research 25, no. 7: 1677-1683.

Morin, R.H. 2006. Negative correlation between porosity and hydraulic conductivity in sand-and-gravel aquifers at Cape Cod, Massachusetts, USA. Journal of Hydrology 316, 43-52, doi10.1016/j.jhydrol.2005.04.013.

Morin, R.H., D.R. LeBlanc, and W.E. Teasdale. 1988. A statistical evaluation of formation disturbance produced by well-casing installation methods. Ground Water 26, no. 2: 207-217.

Nelson, P.H. 2005. Permeability, porosity, and pore-throat size-a three-dimensional perspective. Petrophysics 46, no. 6: 452-455.

Nelson, P.H. 1994. Permeability-porosity relationships in sedimentary rocks. The Log Analyst 3, 38-62.

Oldale, R.N. 1981. Pleistocene stratigraphy of Nantucket, Martha's Vineyard, the Elizabeth Islands, and Cape Cod, Massachusetts. In Late Wisconsinan Glaciation of New England, eds. G.J. Larson and B.D. Stone, 1-34. Dubuque, Iowa: Kendall-Hunt.

Pride, S. 1994. Governing equations for the coupled electromagnetics and acoustics of porous media. Physical Review B 50, no. 21 : $15,678-15,696$.

Purvance, D.T., and R. Andricevic. 2000. On the electricalhydraulic conductivity correlation in aquifers. Water Resources Research 36, no. 10: 2905-2913.

Revil, A., and P.W.J. Glover. 1998. Nature of surface electrical conductivity in natural sands, sandstones, and clays. Geophysical Research Letters 25, no. 5: 691-694.

Shepherd, R.G. 1989. Correlations of permeability and grain size. Ground Water 27, no. 5: 633-638.

Singha, K., and S.M. Gorelick. 2005. Saline tracer visualized with three-dimensional electrical resistivity tomography: field-scale spatial moment analysis. Water Resources Research 41, no. W05023: 17, doi10.1029/2004WR003460.

Smith, R.L., J.K. Böhlke, S.P. Garabedian, K.M. Revesz, and T. Yoshinari. 2004. Assessing denitrification in groundwater using natural gradient tracer tests with $15 \mathrm{~N}$-in situ measurement of a sequential reaction. Water Resources Research 40, no. W07101: 17, doi10.1029/2003WR002919.

Uchupi, E., G.S. Giese, D.G. Aubrey, and D.J. Kim. 1996. The late quaternary construction of Cape Cod, Massachusetts: A reconsideration of the W.M. Davis model. GSA Special Paper 309, 69. Boulder, Colorado: Geological Society of America.

Urish, D.W. 1981. Electrical resistivity-hydraulic conductivity relationships in glacial outwash aquifers. Water Resources Research 17, no. 5: 1401-1408.

U.S. Geological Survey. 2009. Cape Cod Toxic Substances Hydrology Research Site website. http://toxics.usgs.gov/ bib/bib-cape-cod.html.

Waxman, M.H., and L.J.M. Smits. 1968. Electrical conductivities in oil-bearing shaly sands. Society of Petroleum Engineers Journal 8, 107-122.

Wildenschild, D., J.J. Roberts, and E.D. Carlberg. 2000. On the relationship between microstructure and electrical and hydraulic properties of sand-clay mixtures. Geophysical Research Letters 27, no. 19: 3085-3088.

Wolf, S.H., M.A. Celia, and K.M. Hess. 1991. Evaluation of hydraulic conductivities calculated from multiportpermeameter measurements. Ground Water 29, no. 4: $516-525$. 